\title{
STUDENT OPINIONS ON THE EFFECT OF THREE DIMENSIONAL DIGITAL SOFTWARE PROGRAMS FOR SHOWING HUMAN ANATOMY ON ANATOMY EDUCATION
}

\author{
Erengül BODUÇ ${ }^{*}$ \\ ${ }^{1}$ Kafkas University, Faculty of Medicine, Department of Anatomy, 36100, Kars, Turkey
}

\begin{abstract}
The aim of this article is to investigate the effect of three-dimensional digital images on anatomy education through student views. The data collection form prepared with a five-point Likert test was sent to the first and second year students of the Kafkas University Medicine Faculty on the web. 133 students in total answered the questions. When the answers given to the questions were examined, it was observed that there was a significant difference between the answers given by the first and second graders in the third $(\mathrm{P}=0.013)$ and ninth $(\mathrm{P}=0.002)$ questions $(\mathrm{P}<0.05)$. It is thought that the results and opinions obtained from the study will guide the future of anatomy education. Thanks to the student views, it is expected that the study will raise awareness among educators.
\end{abstract}

Keywords: Human Anatomy, Cadaver, Digital software programs, Likert test

${ }^{*}$ Corresponding author: Department of Anatomy, Faculty of Medicine, Kafkas University, 36100, Kars, Turkey

E mail: erenboduc@gmail.com (E. BODUÇ)

Erengül BODUÇ (iD) https://orcid.org/0000-0001-8872-1993

Received: November 22, 2020

Accepted: December 06, 2020

Published: January 01, 2021

Cite as: Boduc E. 2021. Student opinions on the effect of three dimensional digital software programs for showing human anatomy on anatomy education BSJ Health Sci, 4(1): 35-39.

\section{Introduction}

Cadaver is a very important teaching tool in anatomy education (McLachlan et al., 2004). Technological developments in recent years have brought many innovations to the field of anatomy (Lewis et al., 2014). Three-dimensional course software, digital atlas and tablets have been tools that students are interested in and use (Peker et al., 2012; Hoyek et al., 2014). However, the replacement of cadavers by these teaching tools is a highly controversial issue (Murgitroyd et al., 2015).

Anatomy education using cadavers is actually a laborious education model that requires infrastructure (Estai and Bunt, 2016). Laboratory infrastructure should include cadaver tanks, stretcher vehicles carrying cadavers and personnel (Cornwall and Stringer, 2009). In addition, solutions that serve to embalm the cadaver should prevent the risk of infectious diseases and infections (Balta et al., 2019). It is necessary to have done many cadaver dissections in order to be able to master the cadaver and to give lessons with all the details (Granger, 2004). For this reason, having knowledge about cadavers is a success that requires a lot of effort and opportunity (Older, 2004).

When it comes to three dimensional software tools; in recent years, they have benefited greatly from anatomy education (Sugand et al., 2010). Especially, crosssectional and three-dimensional anatomy of the structures has positive effects in increasing the level of knowledge (Gunderman and Wilson, 2005). Sometimes, dissection areas that are not suitable for the cadaver are learned quite clearly with three-dimensional software (Lazarus et al., 2012). However, three-dimensional software cannot provide the perception of reality sufficiently (Kotze et al., 2012). A virtual object of the realness acquired in the cadaver cannot afford much (Lazarus et al., 2012; Biasutto et al., 2006).

In this study, students' views on the state of digital software that has emerged in recent years in anatomy education are included. Education can follow a more dynamic path with student views and the views of young generations can direct education.

\section{Material and Methods}

The study was carried out on the first and second-year medical students of Kafkas University Medicine Faculty in the 2019-2020 academic year. The data collection forms used in the study were prepared on the web and sent to the students by e-mail. One hundred thirty three students (75 from the first class, 58 from the second class) answered the questions in the data collection form. Data collection questions were prepared with a five-point Likert scale (totally agree, agree, undecided, disagree, and totally disagree) (Bahsi et al., 2020). The answers given by the students were automatically analyzed through the web system and the results were obtained through the software. The answer options given were calculated automatically on the system with the calculation of frequency and percentage. The answers are given by the first year and second-year students to the questions were statistically compared with the chi- 


\section{square test.}

\subsection{Statistical Analysis}

The first and second years were compared according to the answers given by the students. Statistical analysis was carried out using SPSS 22.0 version software program for Windows. Descriptive statistics for categorical variables are expressed as frequency and percentage values. A Chi-square test was used in the analysis of categorical data 0 . The results were evaluated at a $95 \%$ confidence interval, and a p-value of $<0.05$ was considered significant.

\subsection{Ethical Consideration}

This study was approved by the ethics committee of the Medicine Faculty of the Kafkas University (Approval number: 2019/12; Decision: 14). The study was performed following the aid of the ethical standards down in the 1964 Declaration of Helsinki and its later amendments.

\section{Results}

The first and second years were compared according to the answers given by the students. Statistical analysis was carried out using SPSS 22.0 version software program for Windows. Descriptive statistics for categorical variables are expressed as frequency and percentage values. A Chi-square test was used in the analysis of categorical data. The results were evaluated at a $95 \%$ confidence interval, and a p-value of $<0.05$ was considered significant. The answer 'I strongly agree' to the first question is higher for the second graders $(62.1 \%)$ than for the first graders (46.7\%). The sophomore students have marked quite decisively. In the second question, the answer 'I strongly agree' is higher in the second grade $(79.3 \%)$ compared to the first grade $(66.7 \%)$. In the third question, the answer 'I strongly agree' is higher in the first grade $(53.3 \%)$ compared to the second grade $(37.9 \%)$. In the second year, although the rate of 'I absolutely agree' (37.9\%) is the highest, 'I strongly disagree' (32.8\%) and 'I am indecisive' (27.6\%) responses are also quite high. The answer I strongly agree on the fourth question is almost equal in first $(40 \%)$ and second grade $(39.7 \%)$. In the fifth question, the rate of undecided students is highest in both the first and second year (Table 1, Table 2). According to the statistics of the Chi-square test of first and second-grade answers, there is a significant difference only in the third $(\mathrm{P}=0.013)$ and ninth $(\mathrm{P}=0.002)$ questions $(\mathrm{P}<0.05)$. Other $\mathrm{P}$ values are given in Table 3.

Table 1. Percentage of frequency (f) that first-year students gave to the questions

\begin{tabular}{|c|c|c|c|c|c|}
\hline First year of the medicine faculty students n:75 & 5 & 4 & 3 & 2 & 1 \\
\hline $\begin{array}{l}\text { Three-dimensional software tools including anatomy } \\
\text { education are the future of anatomy education. }\end{array}$ & 46.7 & 1.3 & 13.3 & 28 & 10.7 \\
\hline $\begin{array}{l}\text { Anatomy education can be supported by three- } \\
\text { dimensional software tools. }\end{array}$ & 66.7 & - & 2.7 & 24 & 6.6 \\
\hline $\begin{array}{l}\text { Anatomy education can be supported with three- } \\
\text { dimensional digital anatomy software, but cannot } \\
\text { replace cadavers. }\end{array}$ & 53.3 & 1.3 & 6.7 & 33.3 & 5.4 \\
\hline $\begin{array}{l}\text { Learning by touching (tactile sense) is a must in } \\
\text { anatomy education. Reality perception cannot be } \\
\text { achieved with digital images. }\end{array}$ & 40 & - & 22.7 & 28 & 9.3 \\
\hline $\begin{array}{l}\text { Learning by touching (tactile sense) is essential in } \\
\text { anatomy education. Reality perception can be } \\
\text { provided with digital images. }\end{array}$ & 10.7 & 5.3 & 34.7 & 21.3 & 28 \\
\hline $\begin{array}{l}\text { Since the fixative solution has an odor in the cadaver, } \\
\text { if a digital transparent cadaver is developed instead, } \\
\text { the lesson can be learned just like in the cadaver. }\end{array}$ & 14.7 & 9.3 & 28 & 22.7 & 25.3 \\
\hline $\begin{array}{l}\text { Cadaver education I do not want it because of the } \\
\text { irritant effect of solutions that protect the cadaver on } \\
\text { respiration and skin. }\end{array}$ & 4 & 18.7 & 25.3 & 9.3 & 42.7 \\
\hline $\begin{array}{l}\text { The structures in the cadaver are complex, I have } \\
\text { difficulty in perception, I think it will be more } \\
\text { comfortable to learn and perceive anatomy with } \\
\text { digital three-dimensional software. }\end{array}$ & 10.7 & 5.3 & 45.3 & 22.7 & 16 \\
\hline $\begin{array}{l}\text { Anatomy lesson should be learned from models and } \\
\text { digital three-dimensional software. }\end{array}$ & 18.7 & 2.7 & 33.3 & 17.3 & 28 \\
\hline $\begin{array}{l}\text { I think that instead of learning anatomy lessons } \\
\text { entirely from mock-up and three-dimensional digital } \\
\text { software, mock-up and three-dimensional software } \\
\text { should be supportive materials in anatomy education. }\end{array}$ & 57.3 & 2.7 & 6.7 & 30.7 & 2.6 \\
\hline
\end{tabular}


Black Sea Journal of Health Science

Table 2. Percentage of frequency ( $f$ ) that second year students gave to the questions

\begin{tabular}{|c|c|c|c|c|c|}
\hline Second year of the medicine faculty students $n: 58$ & 5 & 4 & 3 & 2 & 1 \\
\hline $\begin{array}{l}\text { Three-dimensional software tools including } \\
\text { anatomy education are the future of anatomy } \\
\text { education. }\end{array}$ & 62.1 & - & 10.3 & 27.6 & - \\
\hline $\begin{array}{l}\text { Anatomy education can be supported by three- } \\
\text { dimensional software tools. }\end{array}$ & 79.3 & - & 3.4 & 17.1 & - \\
\hline $\begin{array}{l}\text { Anatomy education can be supported with three- } \\
\text { dimensional digital anatomy software, but cannot } \\
\text { replace cadavers. }\end{array}$ & 37.9 & - & 27.6 & 32.8 & 1.7 \\
\hline $\begin{array}{l}\text { Learning by touching (tactile sense) is a must in } \\
\text { anatomy education. Reality perception cannot be } \\
\text { achieved with digital images. }\end{array}$ & 39.7 & 1.7 & 31 & 17.2 & 10.4 \\
\hline $\begin{array}{l}\text { Learning by touching (tactile sense) is essential in } \\
\text { anatomy education. Reality perception can be } \\
\text { provided with digital images. }\end{array}$ & 25.9 & 8.6 & 27.6 & 24.1 & 13.8 \\
\hline $\begin{array}{l}\text { Since the fixative solution has an odor in the } \\
\text { cadaver, if a digital transparent cadaver is } \\
\text { developed instead, the lesson can be learned just } \\
\text { like in the cadaver. }\end{array}$ & 27.6 & 8.6 & 24.1 & 25.9 & 13.8 \\
\hline $\begin{array}{l}\text { Cadaver education I do not want it because of the } \\
\text { irritant effect of solutions that protect the cadaver } \\
\text { on respiration and skin. }\end{array}$ & 10.3 & 24.1 & 24.1 & 13.8 & 27.6 \\
\hline $\begin{array}{l}\text { The structures in the cadaver are complex, I have } \\
\text { difficulty in perception, I think it will be more } \\
\text { comfortable to learn and perceive anatomy with } \\
\text { digital three-dimensional software. }\end{array}$ & 19 & 6.9 & 24.1 & 27.6 & 22.4 \\
\hline $\begin{array}{l}\text { Anatomy lesson should be learned from models and } \\
\text { digital three-dimensional software. }\end{array}$ & 22.4 & - & 24.1 & 44.8 & 8.7 \\
\hline $\begin{array}{l}\text { I think that instead of learning anatomy lessons } \\
\text { entirely from mock-up and three-dimensional } \\
\text { digital software, mock-up and three-dimensional } \\
\text { software should be supportive materials in } \\
\text { anatomy education. }\end{array}$ & 53.4 & 1.7 & 12.1 & 31 & 1.8 \\
\hline
\end{tabular}

Table 3. P values of first and second year students' answers to each question with chi-square test

\begin{tabular}{|c|c|}
\hline Questions & $\mathrm{P}$ \\
\hline Three-dimensional software tools including anatomy education are the future of anatomy education. & 0.070 \\
\hline Anatomy education can be supported by three-dimensional software tools. & 0.147 \\
\hline $\begin{array}{l}\text { Anatomy education can be supported with three-dimensional digital anatomy software, but cannot } \\
\text { replace cadavers. }\end{array}$ & 0.013 \\
\hline $\begin{array}{l}\text { Learning by touching (tactile sense) is a must in anatomy education. Reality perception cannot be } \\
\text { achieved with digital images. }\end{array}$ & 0.431 \\
\hline $\begin{array}{l}\text { Learning by touching (tactile sense) is essential in anatomy education. Reality perception can be } \\
\text { provided with digital images. }\end{array}$ & 0.073 \\
\hline $\begin{array}{l}\text { Since the fixative solution has an odor in the cadaver, if a digital transparent cadaver is developed } \\
\text { instead, the lesson can be learned just like in the cadaver. }\end{array}$ & 0.270 \\
\hline $\begin{array}{l}\text { Cadaver education I do not want it because of the irritant effect of solutions that protect the cadaver on } \\
\text { respiration and skin. }\end{array}$ & 0.280 \\
\hline $\begin{array}{l}\text { The structures in the cadaver are complex, I have difficulty in perception, I think it will be more } \\
\text { comfortable to learn and perceive anatomy with digital three-dimensional software. }\end{array}$ & 0.146 \\
\hline Anatomy lesson should be learned from models and digital three-dimensional software. & 0.002 \\
\hline $\begin{array}{l}\text { I think that instead of learning anatomy lessons entirely from mock-up and three-dimensional digital } \\
\text { software, mock-up and three-dimensional software should be supportive materials in anatomy } \\
\text { education. }\end{array}$ & 0.843 \\
\hline
\end{tabular}




\section{Discussion}

The innovation and benefits of three-dimensional digital development to the field of anatomy are quite high (Nicholson et al., 2006). In addition to classical systematic anatomy, nowadays, ultrasonographic anatomy, laparoscopic anatomy and cross-sectional anatomy can be taught (Gunderman and Wilson, 2005; Ten Brinke et al., 2014). This is perhaps one of the most valuable and life-saving advantages that technology provides to the medical world (Tan et al., 2012). The issue discussed among anatomists is that the digital system can replace the cadaver (Theoret et al., 2007). There are many articles put forward on this subject. Some anatomists have argued that the digital world is very effective and useful, while others have stated that the digital world will very difficultly replace education with cadaver and reality perception (Theoret et al., 2007; Triepels et al., 2020; Saltarelli et al., 2014; Turhan, 2020). In this article, the subject was presented to the students' opinions with important questions, using the comments and the literature on the effects of digital education on the field of anatomy. Both first and second year students agree to the idea that digital systems will be the future of anatomy education. Even if the number of those who agree with the view that 'anatomy education can be supported by digital 3D software but cannot replace the cadaver' is high in the first and second year, the number of those who do not agree is almost close to the value of those who agree. This may indicate that cadaveric education is still supported by students today, but the trend towards digital education will be more in the following years. 'Learning by touching (tactile sense) is essential in anatomy education. The view that perception of reality cannot be achieved with digital images' participation in the first and second classes is almost equal and more. However, the number of students who are undecided is also quite high. This situation may show that the importance of the concept of learning with touch perception is not adopted by some students.

In order to clarify the uncertainty created by some of the students, the fourth question was posed with a little change, and important values were obtained. 'Learning by touching (tactile sense) is essential in anatomy education. Reality perception can be achieved with digital images.' the rate of those who agree with the opinion is very low. This is desirable. However, the highest rate is undecided students in both the first and second year students. In addition, the total of those who do not participate and definitely do not participate is higher in both the first and second years. In this question, as in the fourth question, the fact that there are undecided people shows that the approach that digital education is adopted more than cadavers is not clear yet. In the sixth and seventh questions, the desire for digital software due to the irritating effect of the fixative solution in the cadaver was examined. While a small portion of the students are affected by irritant solutions, in the first grade, despite irritant solutions, the desire for cadaveric education is higher than the second graders. Apart from that, although the classroom environment with digital cadavers instead of cadavers with irritant solution is mostly rejected by the first graders, the students from the second grade who want this situation are higher than the first grade. The reason why the second graders' approach to digital cadavers is a bit too much may suggest that some students experience exam stress in cadaveric education.

Since the questions asked form a thinking process in the students' minds, the questions were asked in a certain order. As a matter of fact, in the eighth question, the thinking area in the sixth and seventh questions was expanded and clarity was sought. At the end of this situation, it was concluded that the answers given to the eighth question both in the first grade and in the second grade are not certain that digital education will actually provide an easier understanding or replace it than cadaver. The rate of undecided students in the opinion that 'anatomy lessons should be learned from models and software' is high in both first and second year. This is an indication that the new generation is suspicious of the adoption of digital education instead of cadavers. It is observed that students are not willing to learn medicine from digital software instead of a real cadaver.

When it comes to the last question, a question was asked that would actually be the summary of the study. Almost all of the first and second year students strongly agree with the view that 'Anatomy lesson can be a supportive material in anatomy education instead of learning from model and 3D digital software'. It is understood from this that the new generation students have a very positive view of digital technological educational tools. However, the interest in cadavers and the effectiveness of cadavers in the lesson still maintain their place. Therefore, new technology can be useful and effective if integrated with cadaveric education (Pereira et al., 2007; Kharb and Samanta, 2016).

\section{Conclusion}

Cadaver is a very important tool in anatomy education. An effective and useful education model can be created only when the digital course tools offered by the developing technology are integrated with the cadaver.

\section{Limitations}

The study is limited with the answers of students who participated in the survey. The collected information is assumed to be true; the subjects involved in the study were assumed to give their answers honestly. The questionnaire was not a standardized instrument and could be validated in future studies.

\section{Author Contributions}

All task have been made by the single author.

\section{Conflict of Interest}

The author declared that there is no conflict of interest. 


\section{Acknowledgements}

Thanks to Sercan Kenan Başar and Bisher Tahhan, students of the Kafkas University Medicine Faculty, who helped carry out this study.

\section{References}

Bahsi I, Topal Z, Cetkin M, Orhan M, Kervancioglu P, Odabasioglu ME, Cihan OF. 2020. Evaluation of attitudes and opinions of medical faculty students against the use of cadaver in anatomy education and investigation of the factors affecting their emotional responses related thereto. Surg Radiol Anat, DOI: 10.1007/s00276-020-02567-8.

Balta JY, Cryan JF, O'Mahony SM. 2019. The antimicrobial capacity of embalming solutions: a comparative study. J App Microbiol, 126(3): 764-770.

Biasutto SN, Caussa LI, Criado del Rio LE. 2006. Teaching anatomy: cadavers vs. computers? Ann Anat, 188(2):187190.

Cornwall, J, Stringer MD. 2009. The wider importance of cadavers: Educational and research diversity from a body bequest program. Anatomical Sci Educ, 2(5): 234-237.

Estai M, Bunt S. 2016. Best teaching practices in anatomy education: A critical Rev Ann Anat, 208:151-157.

Granger NA. 2004. Dissection laboratory is vital to medical gross anatomy education. The Anatomical Record Part B: The New Anatomist: An Official Pub American Assoc Anatomists, 281(1): 6-8.

Gunderman RB, Wilson PK. 2005. Viewpoint: exploring the human interior: the roles of cadaver dissection and radiologic imaging in teaching anatomy. Acad Med, 80(8): 745-749.

Hoyek N, Collet C, Di Rienzo F, De Almeida M, Guillot A. 2014. Effectiveness of three-dimensional digital animation in teaching human anatomy in an authentic classroom context. Anat Sci Educ, $7(6)$ : 430-437.

Kharb P, Samanta PP. 2016. Blended learning approach for teaching and learning anatomy: Students' and teachers' perspective. J Anatomical Society of India, 65(1): 43-47.

Kotze SH, Mole CG, Greyling LM. 2012. The translucent cadaver: an evaluation of the use of full body digital X-ray images and drawings in surface anatomy education. Anat Sci Educ, 5(5): 287-294.

Lazarus MD, Chinchilli VM, Leong SL, Kauffman Jr GL. 2012. Perceptions of anatomy: Critical components in the clinical setting. Anat Sci Educ, 5(4): 187-199.

Lewis TL, Burnett B, Tunstall RG, Abrahams PH. 2014. Complementing anatomy education using three-dimensional anatomy mobile software applications on tablet computers Clin Anat, 27(3): 313-320.

McLachlan JC, Bligh J, Bradley P, Searle J. 2004. Teaching anatomy without cadavers. Med Educ, 38(4): 418-424.

Murgitroyd E, Madurska M, Gonzalez J, Watson A. 2015. 3D digital anatomy modelling-practical or pretty? The Surgeon, 13(3): 177-180.

Nicholson DT, Chalk C, Funnell W RJ, Daniel S. J. 2006. Can virtual reality improve anatomy education? A randomised controlled study of a computer-generated three-dimensional anatomical ear model. Medical Educ, 40(11): 1081-1087.

older J. 2004. Anatomy: a must for teaching the next generation. Surgeon, 2(2): 79-90.

Peker T, Gülekon N, Tatar I, Sarıkcıoğlu L, Kachlik D. 2012. Three-dimensional imaging and modeling of anatomic structures, sectional and radiological anatomy, and staining techniques. Anat Res Int, 2012: 1-2.

Pereira JA, Pleguezuelos E, Merí A, Molina-Ros A, Molina-Tomás MC, Masdeu C. 2007. Effectiveness of using blended learning strategies for teaching and learning human anatomy. Medical Educ, 41(2): 189-195.

Saltarelli AJ, Roseth CJ, Saltarelli WA. 2014. Human cadavers vs. multimedia simulation: A study of student learning in anatomy. Anat Sci Educ, 7(5): 331-339.

Sugand K, Abrahams P, Khurana A. 2010. The anatomy of anatomy: a review for its modernization. Anat Sci Educ, 3(2): 83-93.

Tan S, Hu A, Wilson T, Ladak H, Haase P, Fung K. 2012. Role of a computer-generated three-dimensional laryngeal model in anatomy teaching for advanced learners. J Laryngology and otology, 126(4): 395

Ten Brinke, B Klitsie PJ, Timman R, Busschbach JJ, Lange JF, Kleinrensink GJ. 2014. Anatomy education and classroom versus laparoscopic dissection-based training: a randomized study at one medical school. Acad Med, 89(5): 806-810.

Theoret CL, Carmel ÉN, Bernier S. 2007. Why dissection videos should not replace cadaver prosections in the gross veterinary anatomy curriculum: Results from a comparative study. J Vet Med Educ, 34(2): 151-156.

Turhan B. 2020. Physiotherapy and rehabilitation students' opinions on anatomy education: a cross-sectional survey study. Physiotherapy Quart, 28(2): 46-51.

Triepels CP, Smeets CF, Notten KJ, Kruitwagen RF, Futterer JJ, Vergeldt TF, Van Kuijk SM. 2020. Does three-dimensional anatomy improve student understanding? Clinical Anat, 33(1): 25-33 